\title{
Online Ticket Booking System for Mumbai Local Trains
}

\author{
Lakshmi Sudha Kondaka \\ Research Scholar, \\ Sathyabama University, \\ Chennai, SIES GST
}

\author{
Shweta Salian \\ IT Dept, SIES GST, \\ Sector V, Nerul, \\ Navi Mumbai \\ Nivedita Sarma \\ IT Dept, SIES GST, \\ Sector V, Nerul, \\ Navi Mumbai
}
Nayonika Roy
IT Dept, SIES GST,
Sector V, Nerul,
Navi Mumbai

\begin{abstract}
The mobile devices are becoming more and more popular and are providing a new notion of communication that we could once only imagine. With respect to Mumbai, one of the major problems faced by the 70 lakh people, who travel by local trains every day, is standing in the long queues for an average of 10-15 minutes to buy a ticket. This often leads to people traveling without tickets at all. This project aims to find a remedy for these 70 lakh people by using an online application to book tickets on their phone. It will reduce the average minimum 3170 minutes they spend standing in the line annually. The user will have a unique user name for their rechargeable account. Whenever a user wishes to book a ticket online, he can log into the application and enter the required details. The ticket will be booked and the fare will be deducted from the account along with the confirmed ticket. This project aims to provide an incredible and much needed solution, which will benefit more than half of the population of Mumbai and make their daily routine easy and enjoyable.
\end{abstract}

\section{Keywords}

Android, MySql, SQLite.

\section{INTRODUCTION}

The application will provide the user with an account upon registration. It will then take the unique user name of each user to $\log$ into the system. The information regarding the travel will be filled by the user through a GUI display. Payment can be done through the account of each user as identified by the user name. After filling the details if the user agrees to proceed then the equivalent 'amount' of the ticket will be deducted from his account. As soon as the payment is done, the ticket will be generated online and given to each user. This information will be stored in the server for later retrieval.

\section{RELATED WORK}

The existing system which is employed by the Center for Railway Information Systems (CRIS) [5], provides a one-time password (OTP) upon booking the ticket from their online app. The user has to feed in the OTP and the phone number into the ATVM machine located at the station. The ATVM machine generates the ticket. The drawback of this system is that the user has to go to the machine to fetch the ticket and it is not completely online.

\section{SYSTEM ARCHITECTURE}

The system architecture in fig. 1 clearly shows how the system will work and how it is going to be executed [3].

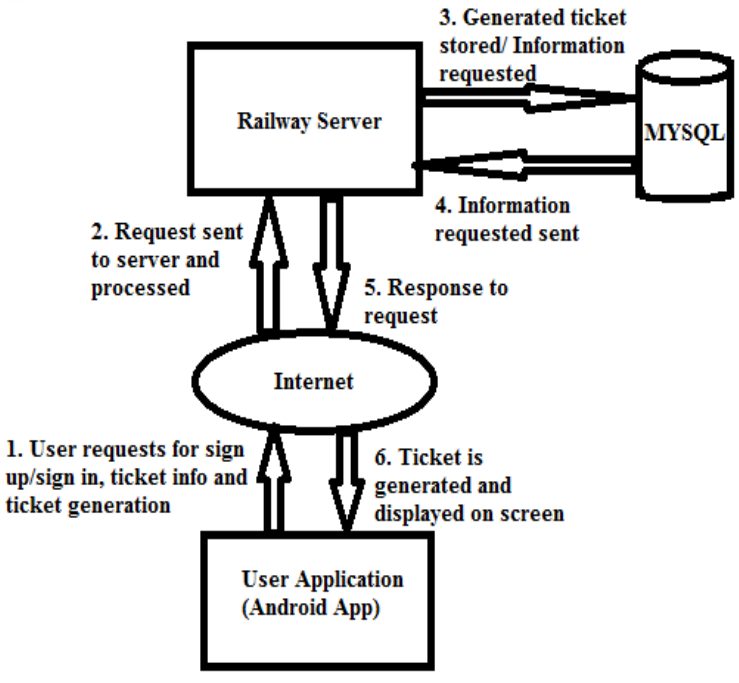

Fig. 1. System Architecture.

The user has to sign up for using the android application. After signing up the user can select the appropriate details for booking the ticket through the book ticket page selected from the menu. Once the book ticket button on the page is clicked, the ticket information is sent to the railway server as an http request via the internet. The train database is made on SQLite database which is the application database. The ticket information and the user detail is then stored in the MySQL

${ }^{[8]}$. The http response from the railway server is sent back to the application. The ticket is displayed in the application itself.

\section{FLOW DIAGRAMS}

The Activity diagram and the Class diagram are as shown below in fig. 2 and fig. 3 . 


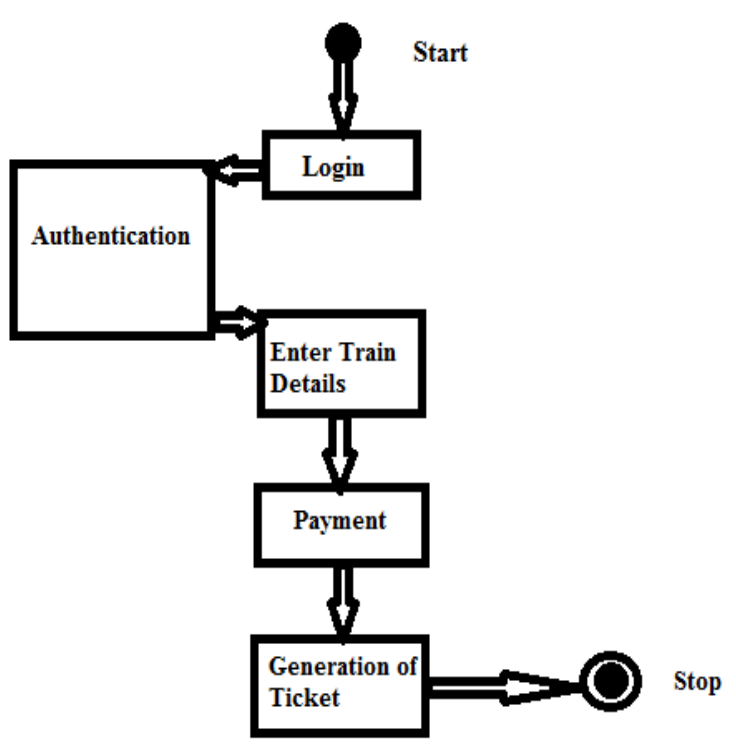

Fig. 2. Activity Diagram

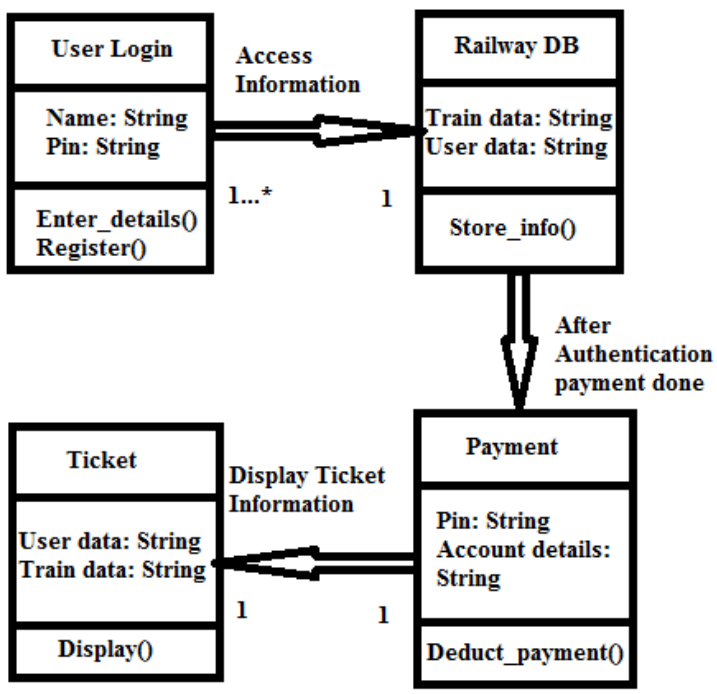

Fig. 3. Class Diagram

\section{WORKING}

\subsection{For installing and running the app}

The user has to download this app from the Google play store. After installing the app, when the user clicks on the app, a login page will pop up as shown in fig. 4b. The user needs to login with his user name and password into the app. If the user is a first time user then he/she has to register first. The registration page consists of details like name, user name (which is their Gmail id), password of their own choice, and their credit/debit card details as shown in fig. 4a.

\subsection{For booking the ticket}

The user will then enter the train details like train source and destination, number of tickets indicating adult or child passengers, and first or second class, as shown in fig. $4 \mathrm{~d}$. The train details will be stored in the database which will be accessed by the application. The details of the train ticket will be sent to the user to verify and proceed to book the ticket using the 'Book' button. After the payment is done, the ticket is generated with details similar to the paper-based tickets ${ }^{[11]}$.

\subsection{For viewing the ticket}

After the user books a ticket, the ticket gets stored in the server. The user can click on the 'View Ticket' button to view the booked tickets from the menu page as shown in fig. 4c. The booked ticket will be displayed as shown in fig. 4e.

\subsection{For Recharging the Account}

The users can recharge their accounts from the application itself as shown in fig. 4f. For the recharge purpose credit or debit card payments can be done. Once the user recharges the account, the user's balance will be updated in the server also.

\subsection{For viewing the Account}

After recharging their accounts the users can view their account balance by clicking on the 'view account' button from the menu. The view account page will be displayed as shown in fig. $4 \mathrm{~g}$.

\section{RESULTS}

The following figures are the screenshots taken directly from the running android application.

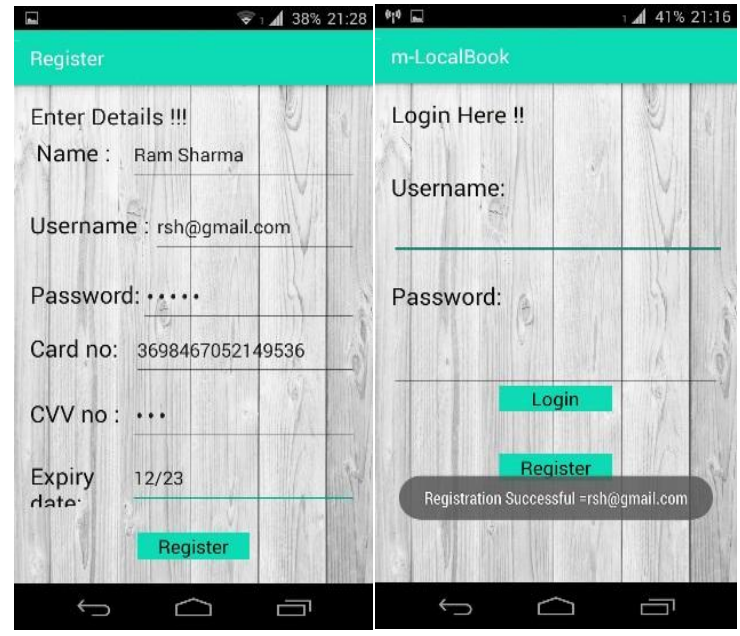

Fig. 4a. Register page.

Fig. 4b. Login page.

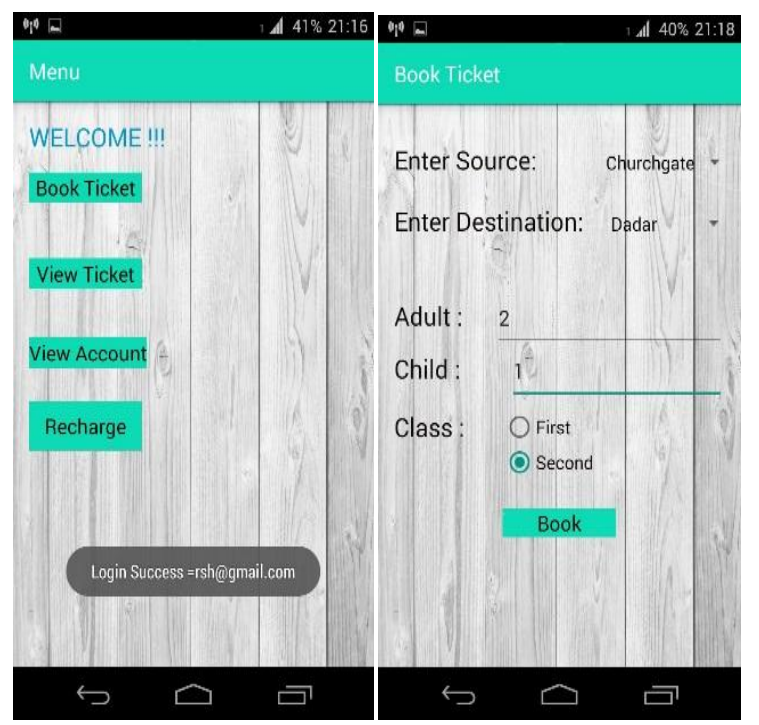

Fig. 4c. Menu page.

Fig. 4d. Book Ticket. 

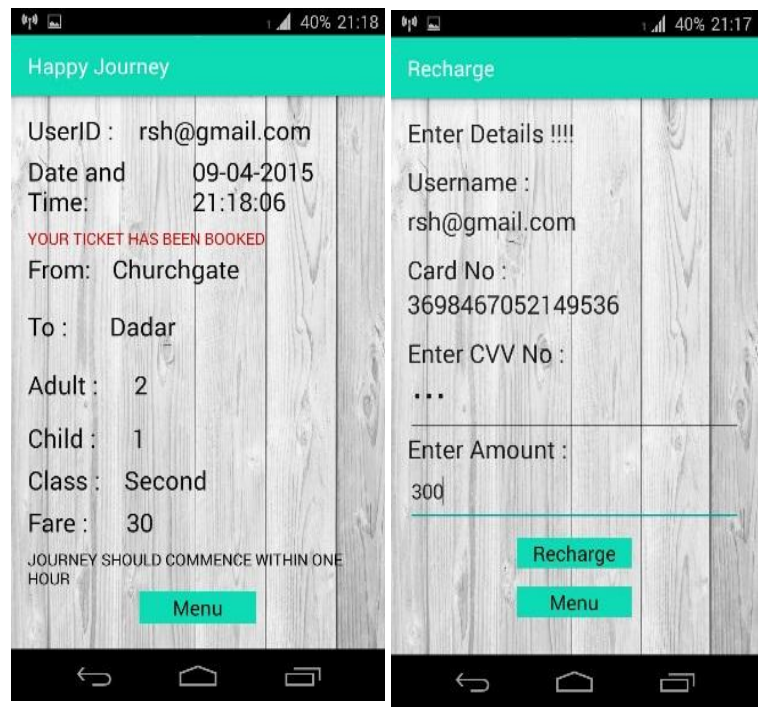

Fig. 4e. View Ticket page. Fig. 4f. Recharge page.

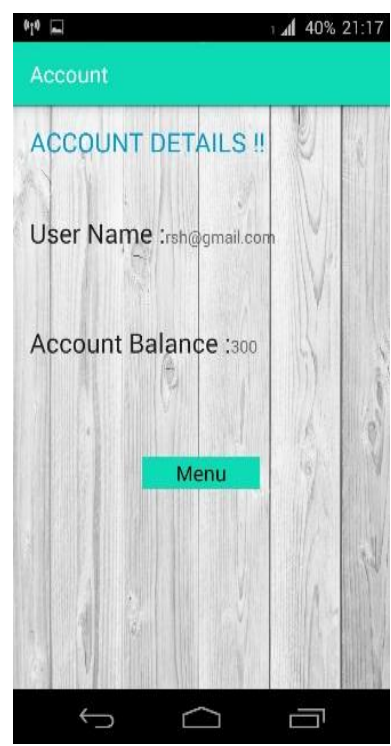

Fig. 4g. View Account page

\section{FUTURE SCOPE}

There is always scope for innovation when it comes to technology. Even our project is no exception. Some possible improvements that can be made in the project in the near future are understanding and making the use of GPS to track down the location of the passenger and enable selection of the nearest station ${ }^{[9]}$. Also understanding the use of SMS facility for ticket display ${ }^{[10]}$.

\section{CONCLUSION}

This project aims to find a remedy for the 70 lakh people by using an android app. It will reduce the time they spend standing in the line, thus making their journey convenient and hassle-free. It will also save paper and be environment friendly.

\section{ACKNOWLEDGMENTS}

Firstly we would like to express our deepest gratitude to our college, S.I.E.S. Graduate School of Technology for encouraging us to do the project that we believed in and really wanted to do. Without their constant support and encouragement in every phase of project preparation, this wouldn't have been possible. We would also like to thank our family and friends who have given us inputs whenever we needed their help. We would like to place on record, our sense of gratitude to one and all who directly or indirectly, have lent their helping hand in this venture.

\section{REFERENCES}

[1] Tushar Dongare, Akshay Babar, Mahendra NivanguneInternational Journal of Emerging Research in Management \&Technology, March 2014-“Android Application for Ticket Reservation with GPS as Ticket Validation."- Dept. Of IT, University Of Pune, India

[2] Sana Khoja, Maithilee Kadam- International Journal of Technical Research and Applications (May-June 2014), "Android Sub-Urban Railway Ticketing Using GPS as Ticket Checker"- Department of Computer Engineering, STES. Smt. Kashibai Navale College Of Engg, Vadgoan(BK), Pune, India

[3] Sadaf Shaikh, Gayatri Shinde, Mayuri Potghan, Tazeen Shaikh, Ranjeetsingh Suryawanshi- International Journal of Advanced Research in Computer Science and Software Engineering January 2014 - "Urban Railway Ticketing Application" Department of Computer Engineering, TCOER, Pune, India.

[4] Neha Sandikar, Rane Dipti and Sachin Pandey- National Conference on New Horizons in IT - NCNHIT 2013 -" Android Railway Ticketing with GPS as Ticket Checker"

[5] Abdul Mateen Ansari, Aftab Alam, Mohammed Mujahid.Barga- International Journal of Emerging Research in Management \&Technology December 2013Department of Information System, King Khalid University, Kingdom Of Saudi Arabia

[6] Sneha Singh, Sagar Chandane, Sneha Bhagat, Prof. D. R. Ingle- IJSRD - International Journal for Scientific Research \& Development "GPS Validation for QR Railway Ticket using Android"-Computer Department, Bharati Vidyapeeth College of Engineering Navi Mumbai, India

[7] Savita Dubey- International Journal of Infinite Innovations in Technology2013-2014 -“ Queue-less Ticketing System for Local Trains”- Dept. Of Computer, University of Lucknow.

[8] Pranjali Kharwade, Vaibhavi Datey, Isha Gujarkar, Vidhi Sharma, Shweta Holey, Vivek Gupta October 2014"Smartphone Application for Railway Ticket Reservation and Validation Using Mobile Network"Department of Computer Engineering, Bapurao Deshmukh College of Engineering, Sewagram, India.

[9] Ramadevi, Murugan and Bharath- International Journal of Computer Science and Engineering (IJCSE) May 2014-“ Railway Ticketing Using GPS In Metropolitan City”- Department of IT, SKP Engineering College, Tiruvannamalai, Tamil Nadu, India.

[10] Mehul Yadav, Sumedh Kurundkar, Anushka Barve, Mrugesh Verekar-International Journal of Scientific and Research Publications, October 2013-“ A QRCode Based Processing for Dynamicand Transparent Seat Allocation"- Vidyalankar Institute of Technology, Mumbai, India

[11] Snehal Kalbhor, Ashwini Mangulkar, Snehal KulkarniInternational Journal for Emerging Trends in Science and 
Technology, 2014- "Android app for Railway Ticketing Using GPS Validation

[12] K. Lakshmi Sudha, Kausthob Das, Mahesh Notani, Saisantosh Shridhar, International Journal of Computer Applications 97(11):5-7, July 2014, Reversible Data Hiding using QR Codes for Android.
[13] Sudha, K.L. ; Sathyabama Univ., Chennai, India ; Mani, R. ; Gabhane, T. ; Jakka, R, Computational Intelligence and Information Technology, 2013. CIIT 2013. Third International Conference on 18-19 Oct. 2013, 257 - 261, Air - Ant Inspired Routing, IEEE explore Digital Library. 